\title{
Migration behavior of maturing sockeye (Oncorhynchus nerka) and Chinook salmon (O. tshawytscha) in Cook Inlet, Alaska, and implications for management
}

\author{
David W Welch*, Aswea D Porter and Paul Winchell
}

\begin{abstract}
Background: Worsening recruitment of Alaskan Chinook salmon over the past decade has created major conservation problems. In Cook Inlet, lucrative Sockeye salmon fisheries are severely limited because of Chinook bycatch, restricting economic opportunity and creating political conflict between user groups. Although Chinook are thought to migrate at deeper depths than other salmon during the marine phase, an inability to quantify the depth difference has prevented regulatory changes to protect Chinook while allowing Sockeye fisheries to operate.

Results: Using a purpose-built acoustic telemetry array, we found that Chinook salmon repeatedly 'patrolled' back and forth in the nearshore fishing area for multiple weeks before river entry (a previously unrecognized behavior) while Sockeye salmon rapidly crossed the area to enter the river. Both species substantially increased migrations speeds at river entry. Migration speeds then progressively dropped, returning to baseline levels about $14 \mathrm{~km}$ upstream of the river mouth. Clear differences in the median depth of marine migration of Chinook (4.8 $\mathrm{m}$ ) and Sockeye $(1.8 \mathrm{~m})$ were evident, enabling us to quantify the potential trade-off between reducing Sockeye harvest and increasing Chinook protection from using shallower gillnets in the commercial fishery. Based on the 16,608 depth measurements collected for Chinook and 3,389 measurements for Sockeye, reducing the vertical depth of surface-hung gillnets to one-half of current maximum depth would potentially reduce the Chinook interception rate by nearly two-thirds, while reducing Sockeye harvests by one-quarter. Alternatively, if commercial fishers were fully compensated for the reduced area of netting by allowing exactly compensatory increases in net length, Sockeye catches could potentially increase to 200\% to $300 \%$ of current levels, but Chinook interceptions would remain similar to current levels despite reductions in net depth. Identifying an intermediate strategy between these two extremes could provide a 'win-win' solution rather than the current zero-sum game between deeply opposed stake-holders.
\end{abstract}

Conclusions: Biotelemetry enabled rapid collection of very large numbers of depth measurements despite relatively few adults being tagged. The collected data have already been used to implement some of the first regulatory changes in the fishery in more than a decade and have identified a potential avenue for political accommodation between opposing user groups.

Keywords: Acoustic arrays, Biotelemetry, Migration, Survival, Chinook, Sockeye, Pacific salmon, Depth of migration, Fisheries management

\footnotetext{
* Correspondence: david.welch@kintama.com

Kintama Research Services, Ltd., 10-1850 Northfield Road, Nanaimo, BC V9S 3B3, Canada
} 


\section{Background}

Steadily worsening returns of Chinook salmon (Oncorhynchus tshawytscha) are occurring over a wide range of Alaskan rivers, including Cook Inlet's Kenai River Chinook population [1-3]. The widespread nature of this decline suggests that the underlying cause of the poor productivity lies in reduced marine survival, but with the marine phase of the life history of Pacific salmon very poorly understood, ecological questions concerning 'where and when' significant reductions in productivity are established remain a matter of conjecture.

In Cook Inlet, the reduced productivity of Kenai River Chinook salmon complicates attempts to manage highly productive co-migrating Sockeye salmon (O. nerka) stocks while ensuring escapement goals are achieved for both species. This has resulted in substantial conflict between multiple user groups: (1) the nearshore surface set gillnet commercial fishery; (2) the 'offshore' commercial drift gillnet fishery; and (3) multiple in-river and marine sport fishing groups [4-18]; an excellent history of the development of the Cook Inlet fisheries is summarized in [19]. Although all fishing groups have an interest in ensuring adequate escapements to support future harvests, they must also contend with the reality that salmon unharvested by their group both reduces their current income and may simply be harvested by another gear sector and not contribute to the spawning escapement.

A particularly contentious issue involves the management of the eastside setnet (ESSN) fishery, sited along the nearshore around the mouths of the Kenai and Kasilof Rivers, and which primarily targets the large Sockeye salmon runs returning to these two rivers. The Kenai River also supports a world-famous Chinook salmon sport fishery and holds the current world record for the largest ever sport-caught Chinook (44 kg). This sport fishing industry was very lucrative but is now in severe decline because of the sharp reduction in the number of Chinook returning to the river and a decrease in the size of those animals. Because the saltwater ESSN fishery targeting the much more abundant Sockeye also catches a substantial proportion of the returning Kenai River Chinook [18], an ability to identify biological differences between the two species that could reduce Chinook catch when Sockeye fisheries are underway would be useful in identifying new management strategies that could better conserve Chinook stocks while retaining (or, ideally, improving) the economic benefits of the Sockeye fishery.

Despite the value of the fisheries, remarkably limited quantitative information is available on the behavior of salmon in Cook Inlet, with most of what is known based on statistical analysis of commercial catches. Previous telemetry studies in other areas generally indicated that Chinook swam deeper in the water column than Sockeye when studies contrasted depth of migration, and generally moved more slowly (the latter possibly due in at least some studies to tagged Chinook being sexually immature and not undertaking strongly directed homing migrations) [20-25]. Drenner et al. [26] summarized much of the telemetry literature by noting that '...vertical position in the water column in coastal areas can vary among species and even within species between relatively short distances on continental shelves' and noting that Sockeye '... choose different depths when swimming in well mixed versus stratified coastal waters', and that '... several species continue to exhibit diel vertical movement patterns during this (that is, the adult) portion of their life'. In Cook Inlet, earlier attempts to identify differences in migration depth by evaluating the depth of fish capture in setnets [27] were considered unsuccessful in providing useful information. In addition, very little useful information is available on migration in the horizontal plane as the two species move through Cook Inlet. Past studies thus provide little guidance as to whether sufficiently pronounced behavioral differences exist to allow useful management interventions in Cook Inlet. Partially as a result of the lack of information, the ESSN fishery has suffered from severe harvest restrictions in recent years in order to attain minimum required escapement goals for Chinook in the Kenai River.

This paper focuses on the behavior of Chinook and Sockeye salmon in the last phase of their marine migration in Cook Inlet and the first phase of their upstream freshwater migration. The specific goal of this study was to identify differences in migration behavior that could reduce the interception of maturing Chinook by the commercial ESSN Sockeye fishery. The ESSN fishery targets Sockeye using fixed surface-hung gillnets ca. $5.5 \mathrm{~m}$ deep operating within the nearshore zone (defined as 1 to 1.5 nautical miles offshore from the high tide mark), but also catches Chinook salmon. Although anecdotal evidence available prior to the start of this study suggested that Chinook migrate deeper than Sockeye and entered the ESSN from the offshore more or less uniformly all along the western boundary of the ESSN, lack of precise information hampers the formulation of regulations that could reduce the capture of Chinook while preserving the Sockeye harvest.

To address this need, between June and August 2013 a marine array consisting of a sparse grid of receivers was sited in eastern Cook Inlet offshore from the mouths of the Kenai and Kasilof Rivers (Figure 1; we term this a 'sparse grid' because the marine receivers were sited too far apart to have overlapping detection zones). Multiple additional acoustic receivers were placed in the Kenai and Kasilof Rivers to monitor the freshwater migration phase. After deploying the tracking array, maturing Chinook and Sockeye were caught in southern Cook Inlet and tagged with an individually identifiable acoustic tag incorporating a pressure sensor (see Methods for details). The receivers 


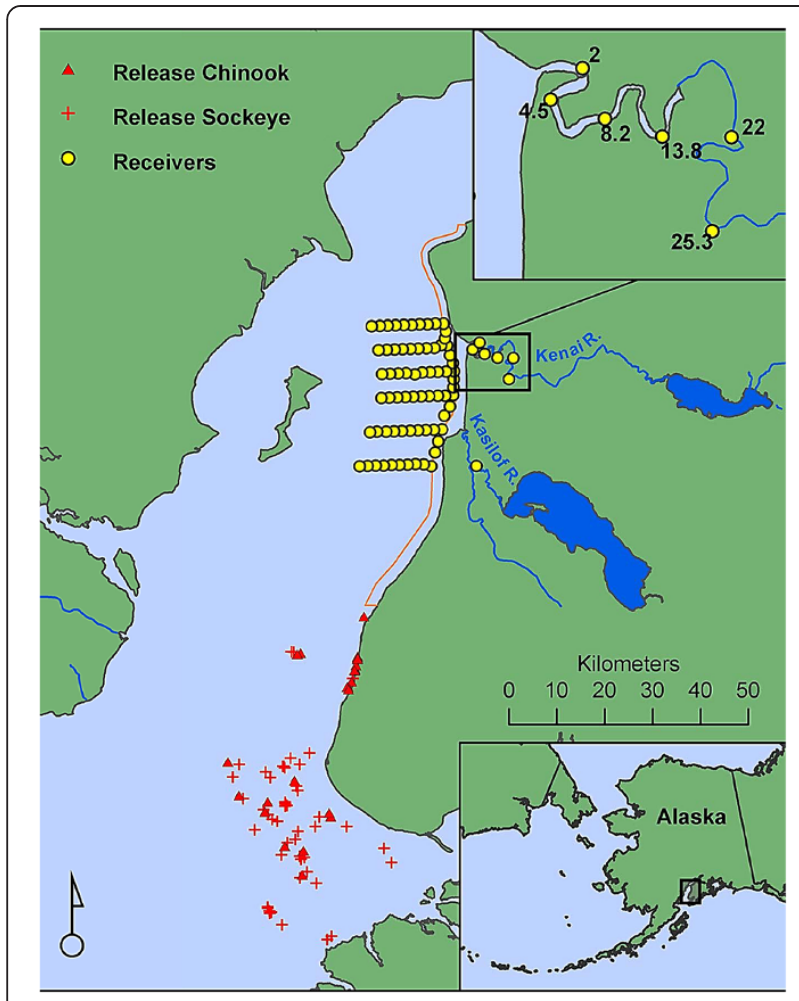

Figure 1 Location of the acoustic telemetry array and release sites for tagged adult salmon. Acoustic-tracking array (yellow dots) and the release sites of acoustic-tagged Chinook (red triangles) and Sockeye (red crosses) salmon in Cook Inlet, 2013. Orange polygon shows the borders of the ESSN fishery.

forming the tracking array then recorded the date and time of all successfully received transmissions of each tagged salmon after release, as well as the depth of the animal at the time of transmission.

\section{Results}

A total of 13 Chinook salmon (52\% of Chinook released) and 27 Sockeye salmon (54\% of Sockeye released) were detected on the marine array, and form the basis for the analysis reported here. Although more Sockeye were detected by the acoustic array, differences in the migration behavior of the two species resulted in far more opportunities for transmissions from Chinook and thus provided a stronger dataset per individual $(\mathrm{N}=19,371$ detections for Chinook and 4,566 detections for Sockeye over the entire array). Differences in swim depth between the species (see Migration depth) were unlikely to substantially affect the number of successful transmissions recorded because depth differences were trivial relative to the likely detection range. Note that the sample size for the depth analysis was reduced because three pressure sensors failed, although these tags successfully transmitted their ID codes (see Data screening under Methods).
At least three Sockeye salmon and two Chinook salmon migrated south after release rather than northwards towards the Kenai and Kasilof Rivers. These fish were caught by fishers who returned the external or internal tags for reward. One additional Sockeye is believed to have migrated to the Chignik River weir (south side of the Alaskan Peninsula), as ADF\&G staff reported seeing a Sockeye tagged with an external disc tag consistent with those used in our study at the weir, but neither the animal nor tag was recovered (Todd Anderson, ADF\&G, personal communication). The longest distance recovery was a maturing Chinook caught by a fisherman near Astoria, Oregon, in the mouth of the Columbia River, in early September. Of those tagged animals recovered to the south of the release point, only one Sockeye had first migrated north and was detected on the marine array before moving south and out of Cook Inlet (this animal was subsequently caught off Kodiak Island). Note that these individuals were removed from all analyses (see Data screening under Methods).

\section{Array performance}

The marine component of the array performed well with $100 \%$ detection of tagged Sockeye and Chinook salmon subsequently recorded entering the Kenai or Kasilof Rivers; most individual freshwater receivers in the Kenai River also detected $100 \%$ of all tagged animals migrating past. It was not possible to evaluate detection efficiency of the two Kasilof River receivers (deployed on opposite sides of the river at the ADF\&G Didson acoustic enumeration site) because no receivers were placed farther upstream, but their detection efficiency may have been poor; only one Sockeye was detected (three detections) and on only one of the two receivers, despite the river being relatively narrow.

\section{Migration routes}

Animation of the detection data (see Additional files 1, 2,3 , and 4 for the animation as static movies at various zoom levels and http://kintama.com/animator/dep/CookInlet2013/ for a dynamic interactive interface) revealed large differences in the pattern of movement, with tagged Chinook salmon migrating almost exclusively as close to shore as instrumentation was deployed (the western offshore boundary of the ESSN), and repeatedly 'patrolling' north and south along the offshore boundary, particularly in the region south of the Kenai River mouth (Figure 2), for up to 20 days before river entry. In contrast, Sockeye salmon migrated primarily offshore and then moved rapidly past the western boundary of the ESSN fishing district (Figure 2), with all but one Sockeye remaining near the ESSN boundary for $\leq 1$ day before entering the Kenai River (Figure 3). In general, both species were detected evenly along the ESSN boundary 


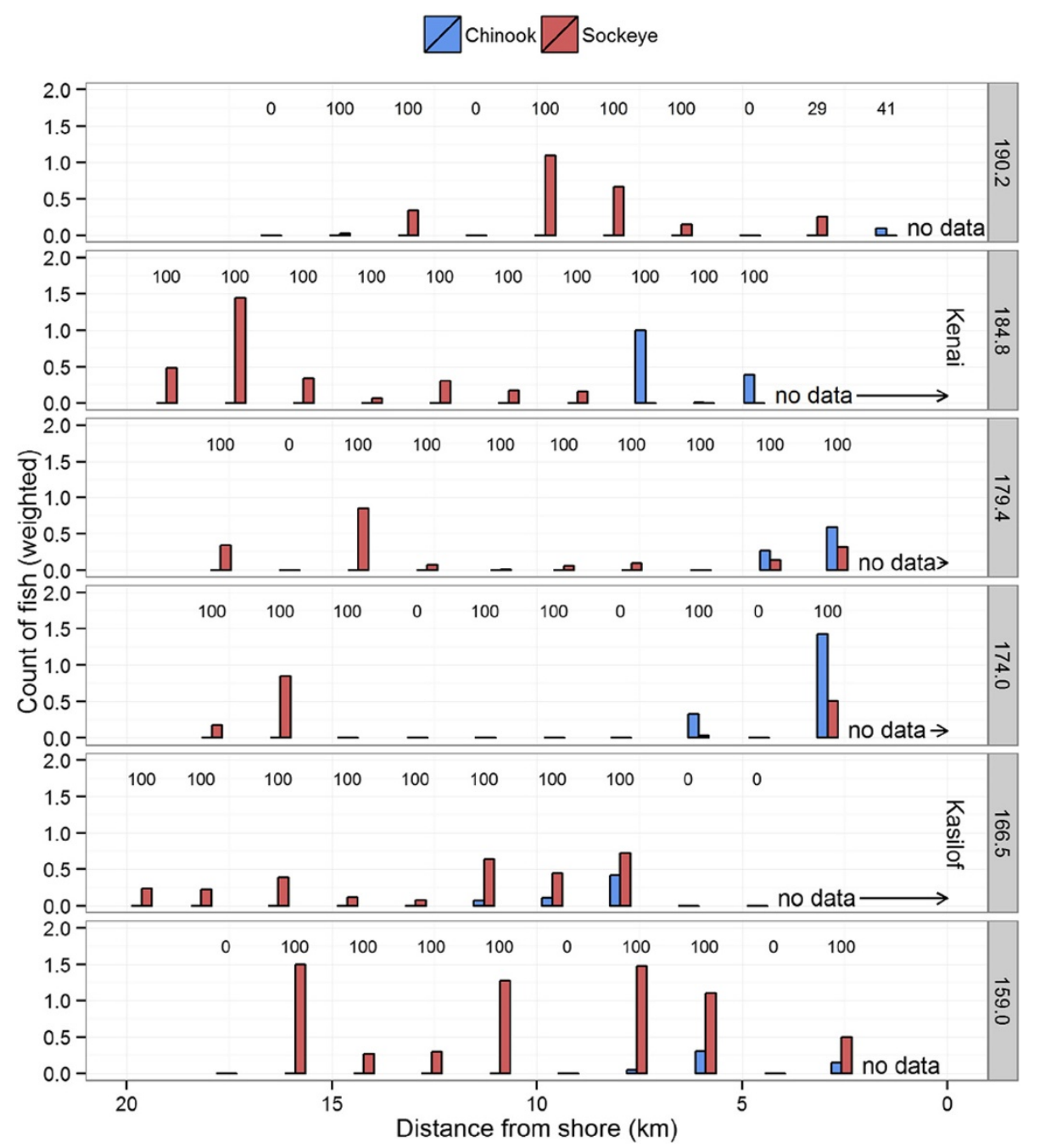

Figure 2 Distribution of adult Sockeye and Chinook salmon migrating over the marine array. If a fish was detected at more than one receiver, a proportion was allocated to the receiver, for example, if an ID code was detected on two receivers, each receiver was assigned a value of 0.5. The values above the bars indicate the proportion of time that the receiver was operational during the season. 'No data' indicates the extent of the inshore region lacking instrumentation. Right hand labels (grey bars) indicate sub-array distances $(\mathrm{km})$ from the center of the release area.

(Figure 4), although more Chinook were detected at the receivers located 6.5 and $10 \mathrm{~km}$ south of the Kenai River, which some individual Chinook seemed to use as an approximate southern limit while milling in the ocean near the Kenai River mouth.

\section{Entry patterns into the ESSN and Kenai River}

There was little evidence that initial entry into the ESSN (defined as first detection on the ESSN boundary receivers) was strongly related to date, stage of the tide, or wind [28]. For river entry, the majority of Chinook and Sockeye initially entered the Kenai River and migrated upstream on either a flood tide or slack water. At river kilometer (RKm) 2, 74\% of Chinook detections and 78\% of Sockeye detections were recorded as the tide was rising. Of the remaining detections at this site, most were recorded at slack water or on a tide that was still ebbing, but nearly slack. Only two individuals were recorded at RKm 2 while the tide was falling significantly; one of these fish did not migrate upriver and the other logged only a single detection on a falling tide as it milled back and forth between the detection sites at RKm 2 and 4.5. At RKm 4.5 , no detections of either species were recorded during ebbing tides. The relationship with the stage of the tide weakened somewhat by RKm 8.2, as $62 \%$ of Chinook detections and $81 \%$ of Sockeye detections were recorded during flooding tides (as would be expected as currents in upriver reaches will be less affected by tides).

Overall, the results suggest that both species took advantage of flood tides to move past the river mouth as quickly as possible and avoided milling movements that would lengthen their residence in the lower river. Once 


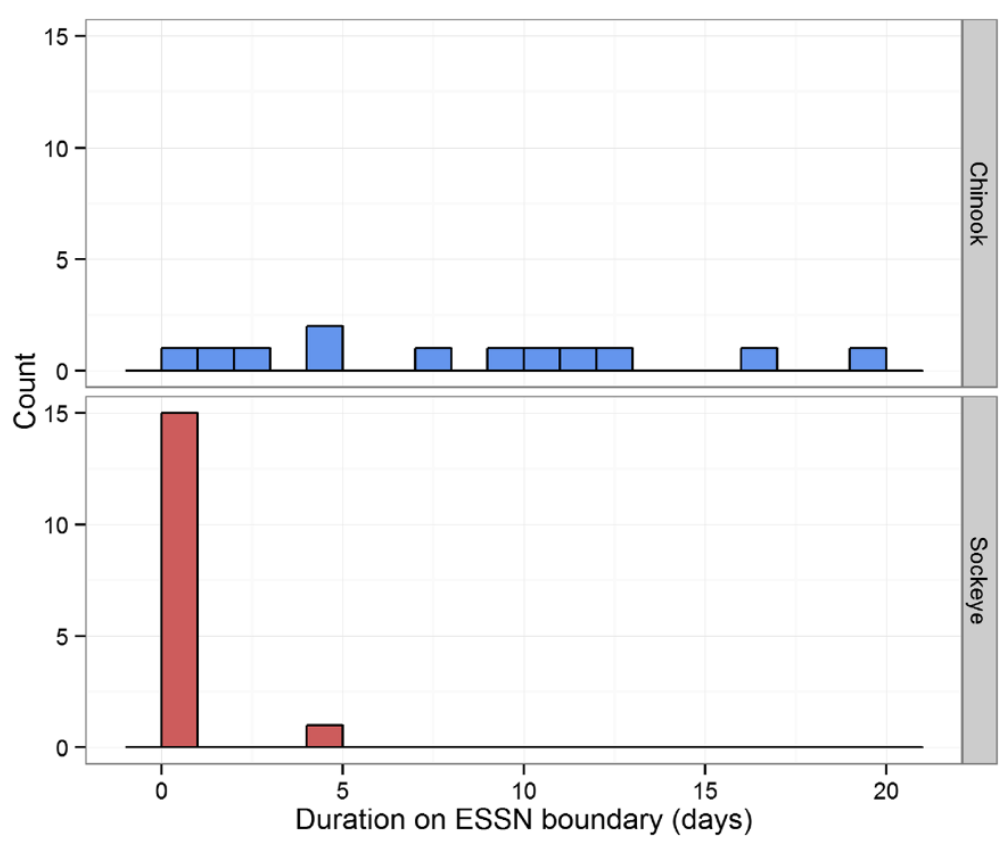

Figure 3 Residence time (days) for Sockeye and Chinook salmon on the ESSN. Residence is defined as the difference between the time of first and last detection on any of the receivers sited along the western boundary of the ESSN.

past this area, both species continued migrating upriver irrespective of the stage of the tide.

\section{Migration speeds}

Travel rates from release to arrival at the marine array and from the marine array to freshwater entry of both Sockeye and Chinook salmon showed no statistically useful relationships with either release date or fish size ( $\mathrm{r}^{2}$ negligible in all comparisons).

After release in southern Cook Inlet, the pattern of migration speeds was similar for both species: slow in the ocean, peaking on river entry, and then slowing again as the fish migrated upriver (Figure 5). The relatively low migration speeds during marine migration likely partially reflect milling behavior, as both species could travel an unknown distance further than the straight line (shortest path) distance between receivers in the ocean. The extensive milling the Chinook displayed before entry to the Kenai River (see animation) is a clear demonstration of this, leading to the much reduced travel rate relative to Sockeye during travel from the marine array to the Kenai River mouth. Travel rates were also somewhat slower for Chinook than Sockeye between release and arrival at the marine array, suggesting that Chinook may have also milled more than Sockeye after release. Both species moved from the array directly into the Kenai River mouth, although Chinook made this transition more rapidly. Once in the river, all but two fish migrated directly upstream without evidence of milling. At upriver sites, the influence of river current presumably contributed to the lower travel rates observed, but the slower migration speed of the larger Chinook relative to the Sockeye suggests that river flow was a relatively minor contributor to travel speed.

\section{Migration depth}

Chinook and Sockeye salmon detected on the receivers sited along the offshore boundary of the ESSN showed significant differences in the depth of migration, with the median migration depth of Chinook below that of Sockeye (Figure 6). Surprisingly, despite the almost complete opacity of the water in Cook Inlet due to suspended sediment, Chinook were apparently several meters above the bottom, suggesting that the Chinook oriented to maintain a water position not directly above the seabed. In contrast, Sockeye were clearly surface oriented. (Some caution is warranted in this interpretation, because if most of the depth data recorded for the Chinook were for locations well inshore of the receivers, then the depth offset relative to seabed depth may be an artifact of the shoaling of the seabed towards the beach).

Receivers sited along the western boundary of the ESSN recorded a total of 15,678 depth measurements for 10 Chinook, and 965 depth measurements for 16 Sockeye, and median migration depths of 4.8 and $1.8 \mathrm{~m}$, respectively. Over the entire marine array, the receivers recorded 16,608 depth measurements for 11 Chinook and 3,389 depth measurements for 25 Sockeye. The large increase in the number of detections for Sockeye 


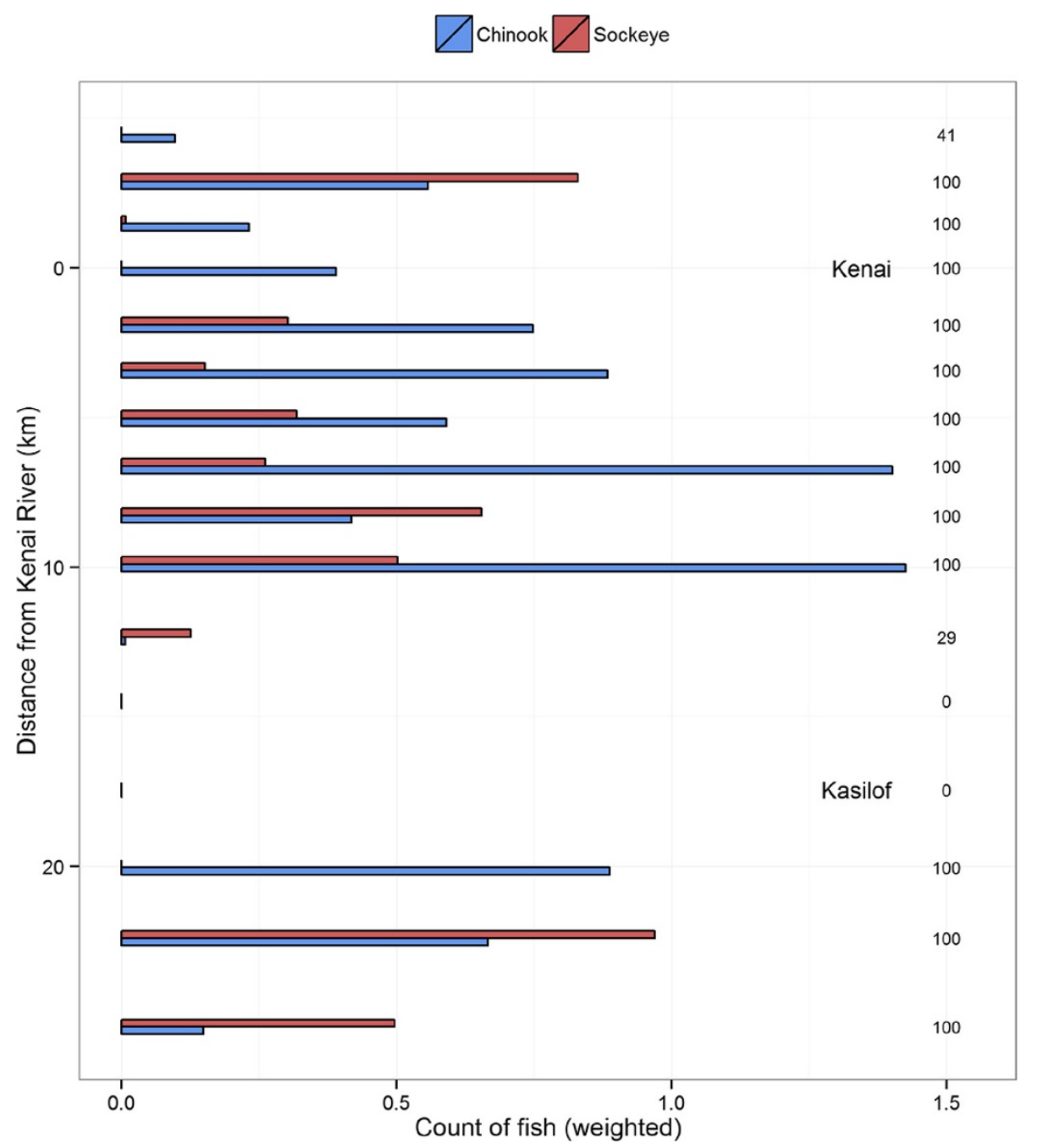

Figure 4 Distribution of adult Sockeye and Chinook salmon on the western edge of the ESSN fishery. If a fish was detected at more than one receiver, an equal proportion was allocated to each receiver detecting it, for example, if an ID code was detected on two receivers, each receiver was assigned a value of 0.5 . The values to the right of the bars indicate the proportion of time that the receiver was operational during the season.

relative to the count along the ESSN boundary reflects their primarily offshore distribution, while the Chinook migrated closer to shore and 10 of 11 animals were only detected along the ESSN boundary. Despite their distribution over deeper offshore water, the median depth for Sockeye over the full marine array was slightly shallower than along the ESSN boundary (1.2 m versus $1.8 \mathrm{~m}$ nearshore); the median depth for Chinook was unchanged at $4.8 \mathrm{~m}$. Thus, irrespective of location, the median depth of migration differed by $\geq 3 \mathrm{~m}$.

To assess the variability in the cumulative depth distributions of the two species on entry to the ESSN, we used a jackknife resampling scheme with individual fish as the replacement units. (Reference [28] reports results using other resampling approaches, and shows that the same conclusions are found). The results (Figure 7) show that there was very little variation between individual
Chinook in the proportion of time spent at different depths, and the cumulative distribution for Chinook increases linearly over the depth range of approximately 2 to $9 \mathrm{~m}$. In contrast, there was a more rapid increase in the proportion of total time Sockeye spent in the surface zone to about four meters depth followed by a gradual tail (which was variable between individuals, leading to the broader width of the shaded area).

The difference between the median depth of the two species (vertical lines) provides a useful measure of the depth separation possible at different times of day or stages of the tide (Figure 8). At night, the difference in median depth was reduced because the Sockeye moved deeper while Chinook moved slightly (average $0.8 \mathrm{~m}$ ) towards the surface. The difference in median depth was also reduced at mid-tide, when tidal currents would be reaching their maximum. However, some of these results 


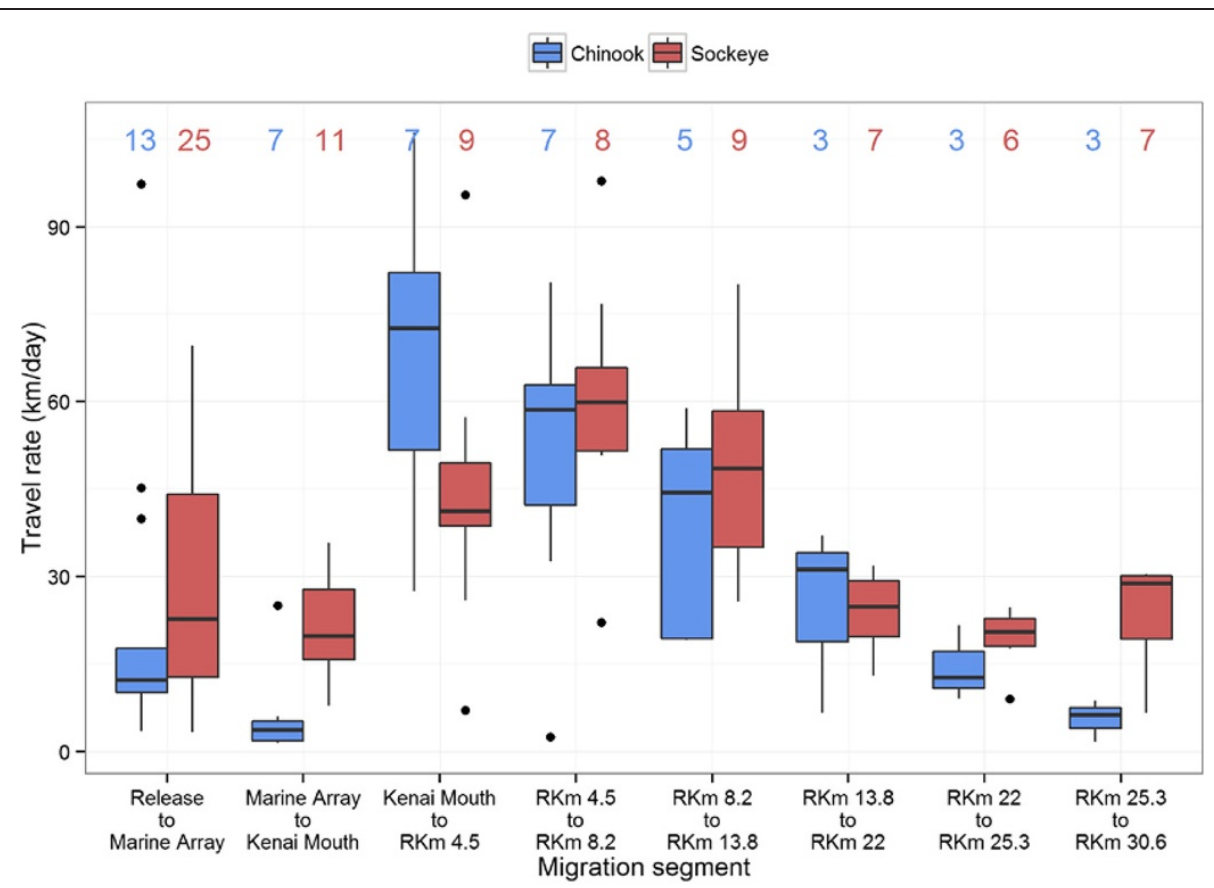

Figure 5 Travel rates ( $\mathrm{km} /$ day) of tagged adult Sockeye and Chinook salmon during different phases of the migration. Time was calculated as the difference between the first and last detections on all receivers sited at the ends of the indicated migration segments, and distance was calculated as the shortest in-water path between detection points.

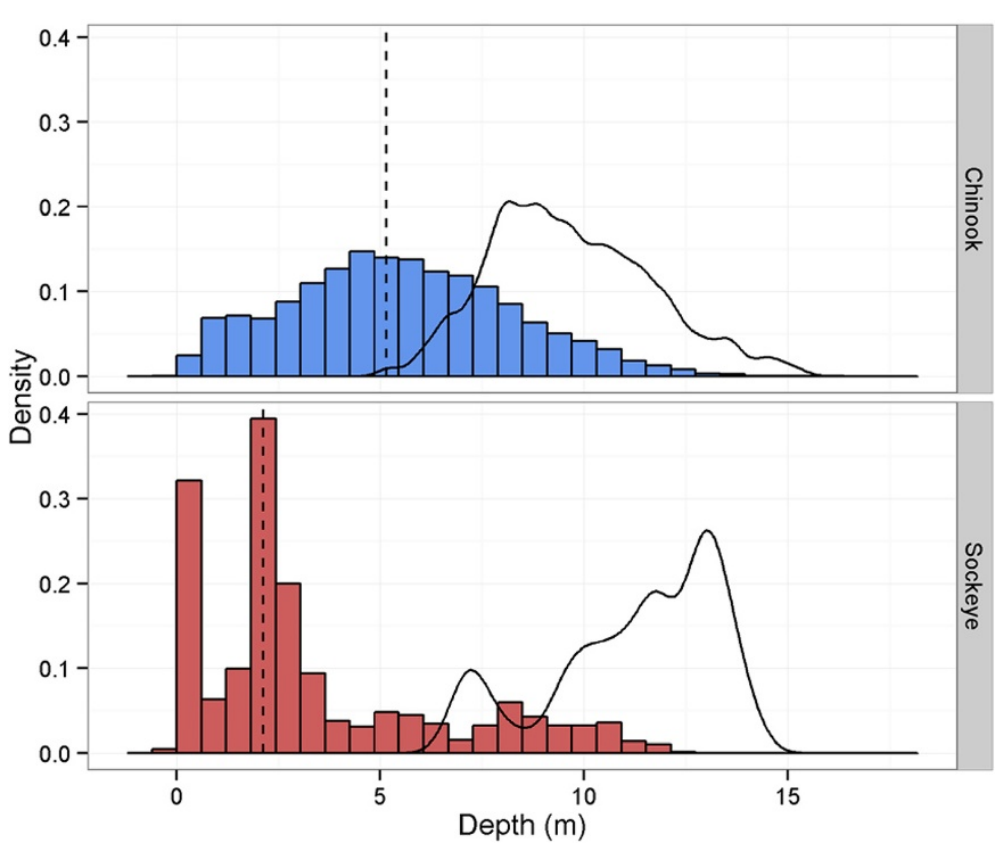

Figure 6 Depth distribution of Sockeye and Chinook salmon detected at the western edge of the ESSN fishing district. Colored bars indicate the depth distributions of acoustic-tagged fish. Black lines indicate the distribution of estimated seafloor bottom depths at the receiver locations, specific for the time each fish was detected. Distributions were calculated using all depth measurements pooled by species. Vertical dashed lines indicate the median depth. 


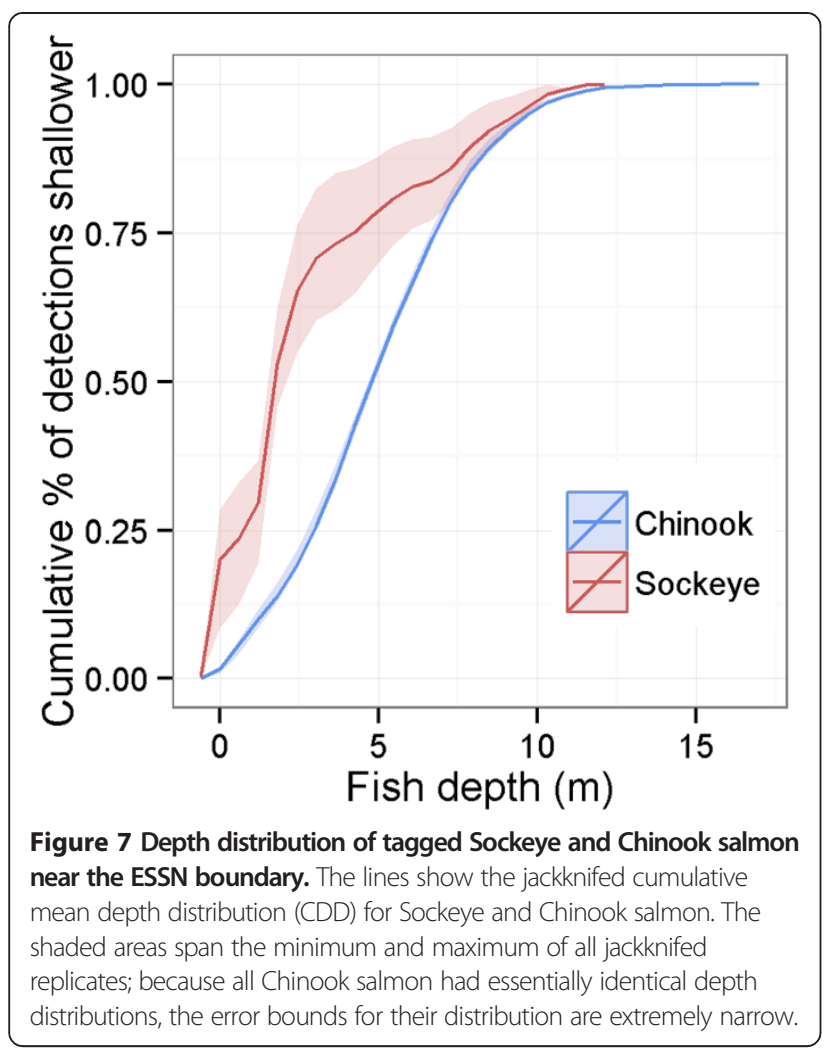

need to be interpreted with caution because data on the depth distribution for Sockeye near the ESSN boundary are quite limited, and become especially limited when apportioned by time or tidal stage. Additionally, the number of detections recorded during mid-tide may not accurately reflect the occurrence of tagged fish near the ESSN boundary because the detection range of the receivers is expected to drop when tidal currents are strong because background noise levels will rise. Overall, during the long days of the Alaskan summer, different stages of the tides appeared to have at best only a minor effect on the depth difference between Chinook and Sockeye.

\section{Discussion}

Several novel results from the present study advance knowledge on the behavior and distribution of Chinook salmon in the ocean, especially the repeated north-south marine movements recorded in the nearshore ocean prior to river entry. The original belief was that Kenai River Chinook entered the ESSN more or less uniformly along the offshore (western) boundary of the ESSN fishery because Chinook harvest rates were similar everywhere within the ESSN. In contrast, our data show that the similar catch rates observed are probably due to the extended milling behavior as Chinook tarry in the nearshore for days or weeks before finally entering freshwater - a behavior unanticipated from interpretation of the catch data. In contrast, tagged Sockeye salmon were primarily distributed further offshore and transited rapidly through the ESSN to reach the river, providing only a brief window of opportunity to catch them within the ESSN. Both species then migrated past the river mouth at high speeds (primarily on flood tides or at slack water) before slowing down again upriver.

The timing and speed of river entry seems likely to have evolved to allow the fish to avoid predators congregating at the choke point formed by the river mouth. Similar behavior was noted for Chinook entering the Columbia River mouth by Strange [29], who also concluded it was likely due to predator avoidance. Unfortunately, this behavior exposes Chinook to greater risk of capture in the commercial setnet fishery, because they remain present for extended periods of time in the ESSN relative to the target species, Sockeye (Figure 3).

In general, Chinook migrated approximately $3 \mathrm{~m}$ deeper in the water column than Sockeye under both high and low tides and particularly during daylight hours. For both species, depth in the water column bore little relationship to bottom depth. This behavioral difference potentially provides the basis for changes to the allowable depth of setnets that could (most simply) trade off some reduction in Sockeye harvest for an increase in Chinook escapement or (in a more sophisticated approach) potentially maintain or even increase Sockeye harvest while reducing Chinook harvest levels. In other words, it might be possible to simultaneously improve the economic returns to the State of Alaska from the Sockeye fishery while still enhancing Chinook conservation.

The latter approach is of particular importance because simply reducing the maximum allowable setnet depth to improve Chinook conservation reduces the income of the ESSN fishers, exacerbating the political friction between groups because one group's gain comes at the other group's loss - essentially a zero sum game. (In fact, the current preferred solution of the in-river sport fishing groups would be to have zero-depth nets complete elimination of the ESSN fishery; a similar comment applies in reverse to the ESSN group). Because the current situation is that any gains for one side will be perceived as a loss by the other, management change will be slow since each group will exert political pressure to block initiatives favorable by the other side.

To quantify the nature of the trade-off possible, consider the basic data on the relative proportion of time the two species spend shallower than any given depth and are thus exposed to harvest (Figure 9A). Irrespective of whether we consider the depth data collected along the western boundary of the ESSN or collected further offshore, a clear species-specific difference in the proportion of time spent in near-surface waters is evident. Using these data, it is possible to calculate the projected harvest for the two species relative to the standard (45 mesh depth) net if the nets were made shallower or 


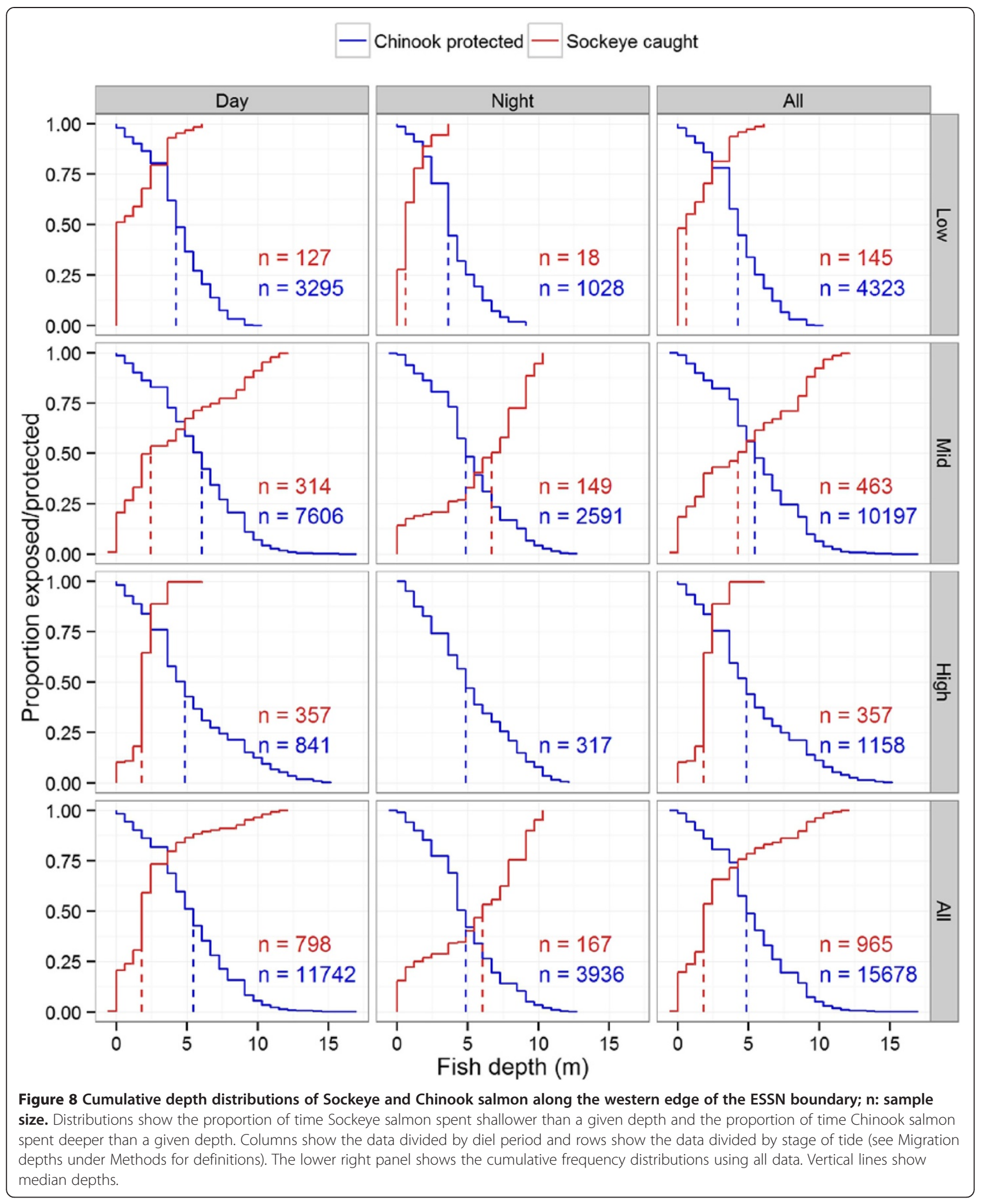

deeper (see Methods for details). As net depths are reduced (Figure 9B), a more rapid decline in Chinook harvest rates is initially expected, but potentially important
Sockeye harvest would be foregone by ESSN fishers. For example, the projected harvest of Chinook initially drops more rapidly than the harvest of Sockeye until net 

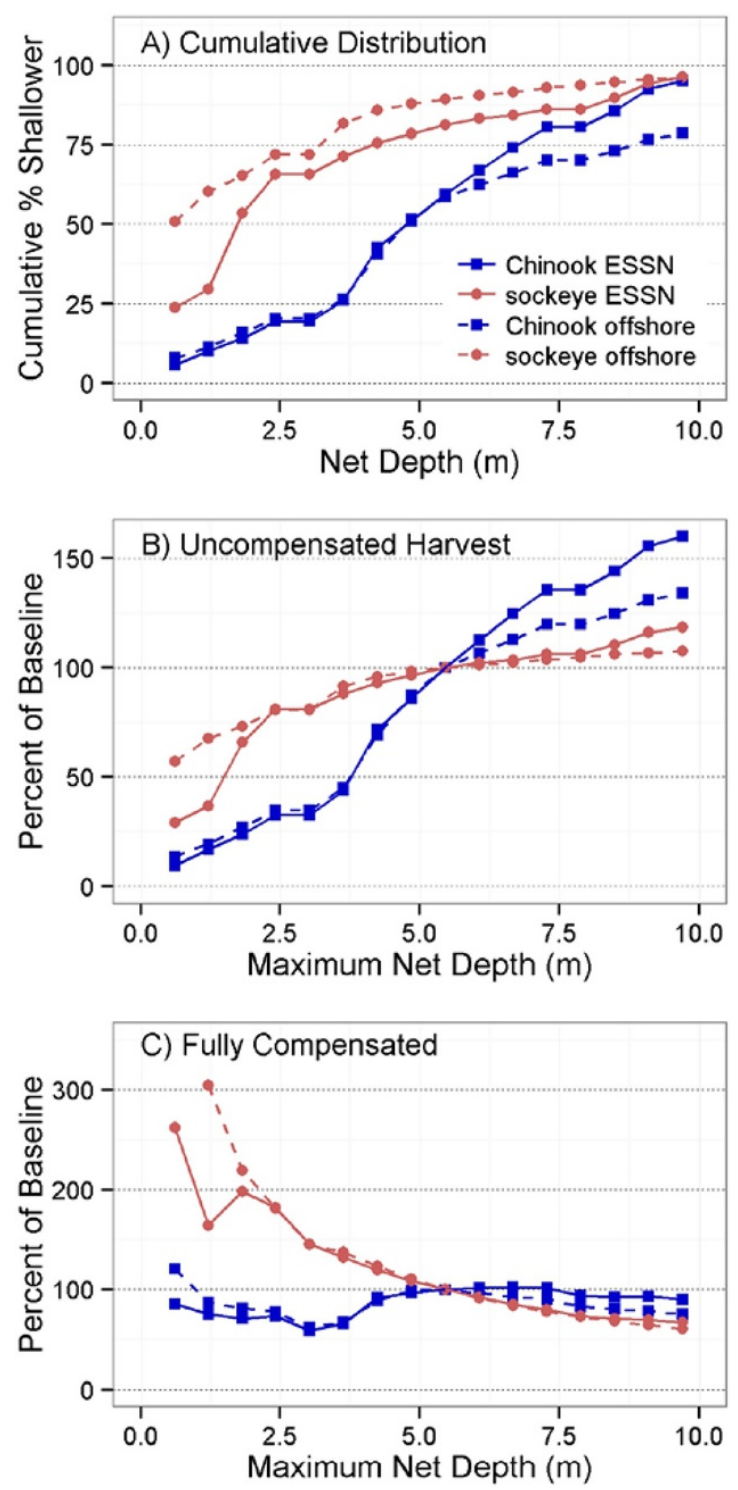

Figure 9 Potential impact of changing net depth on Sockeye and Chinook salmon harvest levels. (A) Comparison of Chinook and Sockeye salmon cumulative depth distribution along the western boundary of the ESSN and on all offshore marine receivers (those not sited along the boundary). (B) Projected relative harvest if maximum allowable net depth was varied from the 45 mesh standard (ca. $5.5 \mathrm{~m}$ ), but net length was held constant. (C) Projected harvest if the net area is held constant by increasing the length of the nets to exactly compensate for reducing the net depth. Large gains in Sockeye Salmon harvests are predicted under (C), while only small gains in Chinook salmon conservation can be achieved (and only for nets $<4 \mathrm{~m}$ deep). If net length is kept invariant, (B) predicts that Chinook salmon losses would decrease to approximately $30 \%$ of baseline at a net depth of $3 \mathrm{~m}$, while Sockeye Salmon harvest would be approximately $80 \%$ of current values. As discussed in the text, relative harvests are calibrated to absolute depths from tag sensors, but maximum net depths are assumed to be directly proportional to the number of meshes; if the effective maximum depth of the net is different (because mesh size varies or nets billow under strong tidal currents), this would amount to a lateral shift of the curves along the $x$-axis. depths are less than $3 \mathrm{~m}$. For nets of $2.5 \mathrm{~m}$ depth, the projected harvest rate of Chinook would be about onethird of the current level of interception, while Sockeye harvest would remain at about four-fifths (80\%) the current level. Although this is a promising potential improvement in Chinook conservation, any affected group of individuals threatened with a $20 \%$ loss of income would be expected to resist regulatory change.

Alternatively, if ESSN fishers were compensated for the use of shallower fishing gear by allowing proportionately longer nets that exactly preserve the area of net fished, major increases in Sockeye harvests could be obtained (Figure 9C). However, in this case little or no reduction in Chinook interception is projected; again, the regulatory approach is close to a zero-sum game because those primarily interested in Chinook conservation would perceive this approach as providing negligible reductions in Chinook interception, and would thus politically oppose this solution.

Importantly, nearly any trade-off between the two extremes outlined in Figures $9 \mathrm{~B}$ and $\mathrm{C}$ (that is, allowing some - but not fully - compensatory increases in net length) would see benefits accrue to both groups, and thus potentially align their political interests. Further analysis of the trade-offs is outside the scope of this paper, but our results suggest that identifying the increases in net length necessary to just maintain ESSN Sockeye harvests as net depth was reduced would be a useful starting point for negotiations.

Such an outcome could completely change the dynamics of the current Cook Inlet 'fish wars', because it would align the interests of two deeply opposed user groups. Potentially, the combined reduction in harvest and Chinook killed but lost from the nets before harvest could boost Chinook escapements to well above the minimum required escapement goal because it is thought that the drop-out rate of large Chinook caught and killed in the small mesh Sockeye gillnets and which fall out of the nets unseen in the turbid waters of Cook Inlet may be large. Commercial fishers working in the Bristol Bay Sockeye fishery made several comments at the 2014 Board of Fisheries meeting that despite substantial effort to harvest the valuable Chinook caught and killed in Bristol Bay Sockeye nets, 'most' were not recovered as the net was brought in because the dead Chinook dropped out before they could be secured. This suggests that unrecorded losses of Chinook from Cook Inlet Sockeye nets could be substantial.

Our current results thus allow considerable insight into the utility of shortening the maximum depth of ESSN set gillnets and recent regulatory changes. In February 2014, the Alaska Board of Fisheries adopted changes to the Kenai River Late-Run Chinook Salmon Management Plan [30,31]. The language (5 AAC 21.359) 
states in part '...the number of set gillnets operated may also be restricted to either (i) three set gillnets that are each not more than 35 fathoms in length and 29 meshes in depth or two set gillnets that are each not more than 35 fathoms in length and 45 meshes in depth; or (ii) two set gillnets that are each not more than 35 fathoms in length and 29 meshes in depth or one set gillnet that is not more than 35 fathoms in length and 45 meshes in depth'.

These changes were implemented in part by results from our 2013 telemetry study indicating that Chinook were indeed migrating deeper than Sockeye and in part by the results of an experiment reported at the Board of Fisheries meeting by a respected long-time ESSN fisherman, Gary Hollier, who conducted experimental fishing trials in 2013. Hollier reported that Sockeye catches seemed very similar using shortened 29 mesh nets fished in tandem with standard 45 mesh nets.

Based partly on this information, the Board of Fisheries developed the language cited above. What are the implications? The proposed regulatory change would modify the area of mesh fished by reducing the depth to 29/45 (approximately $64.4 \%$ of the former 45 mesh standard) and compensating for the reduced depth by increasing the number of standard length nets from either two to three or one to two (depending upon whether the criteria defining (i) or (ii) apply). In effect, in terms of the area of the fishing net permitted, the regulations would either be essentially neutral $(0.644 \times 1.5=0.97)$ or offer an inducement of an increase of up to $29 \%(0.644 \times 2=1.29)$ in total allowable net area in compensation for reducing the maximum depth of the net fished.

What would be the potential effect on Sockeye and Chinook harvest? As a first step, consider the effect of reducing net depth without increasing the length (See Methods for details). Assuming for simplicity that the setnets hang straight down, 45 mesh nets are estimated to have an average depth of 18 ' $(5.5 \mathrm{~m})$, so 29 mesh nets would hang down $5.5 \mathrm{~m} \times 29 / 45=3.5 \mathrm{~m}$. Sockeye and Chinook respectively occupied the top $5.5 \mathrm{~m}$ of the water column near the ESSN boundary for 81\% and 59\% of the time, and thus were exposed to harvest in standard nets for that proportion of time. If nets were reduced to $3.5 \mathrm{~m}$ in depth (29 meshes), exposure to capture would decrease from $81 \%$ to $71 \%$ for Sockeye, and from $59 \%$ to $26 \%$ for Chinook. Thus relative to the baseline harvest $(h)$ achieved using standard nets, Sockeye harvest in reduced-depth nets would be projected to decrease to $h_{S}=0.71 / 0.81=88 \%$ if no compensatory modification to fishing time or net length was allowed, and to $h_{C}=0.26 / 0.59=44 \%$ for Chinook. (Using depth data for the offshore region provides similar values).

Multiplying the reduced exposure to harvest from shallower nets by the increase in allowable net length under proposed regulation (i) of $150 \%$ and (ii) of $200 \%$, yields a projected Sockeye harvest of $h_{S}=132 \%$ (approximately $176 \%$ relative to previous levels) and a projected Chinook harvest of $h_{C}=66 \%$ to $88 \%$ (as per eqn. 4). Taking midpoints for simplicity, Sockeye harvests would increase by $54 \%$, while Chinook harvest in the ESSN might decrease by $25 \%$. This is an important gain because recent forecasts of returning Kenai River Chinook are typically at the bottom end of the allowable escapement range before fishing because of poor ocean survival.

Several important caveats still need to be recognized. First, although the number of depth measurements is large, the number of tagged Chinook $(\mathrm{N}=11)$ and Sockeye $(\mathrm{N}=25)$ that they are based on is small and could include individuals from non-Kenai stocks. Second, nearly all depth measurements for Chinook were made by the receivers sited along the offshore (western) edge of the ESSN fishing zone, so our observations describe the relative depth distribution in the two species for only the farthest offshore part of the ESSN area. Although the depth distribution of Sockeye along the ESSN boundary is similar to that observed even farther offshore, we do not know if a similar conclusion also applies to Chinook, which seem to be distributed farther inshore. Third, saltwater sport fishers typically troll for Chinook very near the beach in only 1.5 to $3 \mathrm{~m}$ water depths; unless nets are made extremely shallow (or regulated so that they are only fished farther offshore in the deeper waters of the ESSN), substantial interception of Chinook may still occur because the net will reach the bottom. Fourth, the exact changes in Chinook and Sockeye harvest are somewhat sensitive to the assumed depth of a standard net that potential harvests are calculated relative to (essentially, because the shape of the cumulative distribution changes with depth, so the change in harvest levels is influenced by the chosen starting point). Fifth, the behavior of deep or shallow nets when fished over the entire tidal cycle is unclear; it is possible that deep nets rise up off the bottom more than shallower nets due to the greater resistance of the former in strong tidal currents, potentially negating at least part of the assumed difference in net depth at some stages of the tide.

Finally, the management issues in Cook Inlet are more complex than the simple two group dynamics we have described in this paper; in reality, there are other fishing groups (offshore commercial driftnet and multiple inriver interest groups) with competing interests, and other Cook Inlet river systems whose salmon are also intercepted. A fully satisfactory management plan would require tagging at least three salmon species (coho, Chinook, and Sockeye) and designing and operating an array that covered much more geographic area within Cook Inlet to better understand the stock-specific 
migrations of each species in both two and three dimensions within Cook Inlet.

\section{Conclusions}

Our 2013 pilot study identified a significant difference in migration depth between Chinook and Sockeye salmon returning to Cook Inlet. Beyond improving our basic ecological knowledge of migration during the final phase of the ocean migration, our results provide the raw material for predicting how potential harvest of the two species might change if net depths other than the Board of Fisheries' somewhat arbitrary '29 mesh' choice were selected. This approach has considerable promise in identifying a mutually beneficial solution that aligns the interests of two opposing user groups, by simultaneously maintaining (or possibly increasing) economic revenue to the ESSN Sockeye fishery while increasing Chinook escapement levels. Although the limited nature of the pilot study needs to be recognized, the collected telemetry data should allow the two parties to mutually explore the range of trade-offs possible between Sockeye revenue and Chinook conservation.

\section{Methods}

\section{Marine array}

Cook Inlet has the second highest tides in the world, and correspondingly strong tidal currents, requiring particularly careful engineering of the deployment systems for housing the tracking receivers (VEMCO VR2W). To address the key biological questions, we designed a marine telemetry array consisting of 70 acoustic receivers, deployed in early June to form a sparse grid starting at the western (offshore) edge of the eastside setnet (ESSN) fishery area and extending westward approximately $15 \mathrm{~km}$ or one-third of the way across Cook Inlet (Figure 1). The grid consisted of a series of six east-west lines spaced approximately $5 \mathrm{~km}$ apart. We deployed 10 receivers in each line spaced ca $1.7 \mathrm{~km}$ apart. We also sited two receivers midway between each line (for a total of 10 units) to provide greater resolution along the outer boundary of the ESSN fishing zone. We monitored the boundary to the ESSN rather than the fishing district itself because it was initially believed that Chinook entered the ESSN from the offshore more or less uniformly along the western boundary and were caught soon after entry. Second, the deployment and maintenance of acoustic equipment within the ESSN is difficult because the area is shallow, rocky, and exposed to strong currents and wave-driven surge.

We recovered and successfully uploaded 54 of the receivers in late summer (27 August to 5 September 2013). The remaining receivers either were displaced by fishing activities and then returned by members of the public prior to recovery of the marine array, or lost.

\section{Freshwater array}

To monitor the freshwater phase of the migration, 11 receivers were deployed in the Kenai River between 9 June and 2 July. Single receivers were installed at RKms 2, 4, and 25.3, and paired receivers were installed at RKms 8.2, 13.8, 22.0, and 30.6. An additional two receivers were deployed in the Kasilof River at RKm 12.1. All freshwater deployments were successfully recovered and downloaded 8 to 24 August.

\section{Tags}

All acoustic tags used in this study (custom programmed VEMCO V16P-3H; $16 \mathrm{~mm}$ diameter $\times 64 \mathrm{~mm}$ long; $26 \mathrm{~g}$ in air) were equipped with a pressure sensor reporting depth at the time of transmission. Stated depth resolution $(0.6 \mathrm{~m})$ and accuracy $( \pm 6.8 \mathrm{~m})$ for the sensors on the company's website indicated rather large inaccuracies relative to the potential differences in depth of migration for Chinook and Sockeye salmon that were expected. However, in follow-up discussions with VEMCO staff it became clear that the resolution and accuracy data were provided by the sensor manufacture and there was no clear statistical definition accompanying the use of these terms.

In order to assess the accuracy of the pressure sensors in the acoustic tags, we deployed six tags previously returned from the fishery and eight receivers in Sproat Lake, B.C., between 23 October and 4 December 2013. Three tags were deployed at each of 5.2 or $3.0 \mathrm{~m}$ below the surface (close to the mean recorded depth of the Chinook and sockeye) on a fixed sub-surface mooring. Three major rainfall events occurred while this study was running which increased the water level in the lake and thus the depth of the tags. A water level gauge at the outflow of Sproat Lake (Environment Canada hydrometric station 08HB008) indicated that water levels there changed by a maximum of $0.9 \mathrm{~m}$ and thus should be closely correlated to water level changes above the tags. To limit the effect of water level changes, we used only sensor transmissions on days where the water level at the gauge was within $0.25 \mathrm{~m}$ of its level on the day the tags were deployed ( 23 October). Of the tags used, one depth sensor failed (although it continued transmitting), and one tag stopped transmitting before the end of the study. Apparently the tag that stopped transmitting had not been turned off when originally recovered from the fishery and the programmed kill time of 150 days post-activation was exceeded during the lake deployment. The results show that the average difference between the approximate deployed depth of the tags and the average depth reported by the remaining sensors was $0.3 \mathrm{~m}$ (range 0.1 to $0.58 \mathrm{~m}$; see [28] for details). Because the tags were programmed to have a depth resolution of $0.6 \mathrm{~m}$, this indicates that the tags were generally within 
1 interval of true depth and that instrument errors were substantially smaller than the difference in speciesspecific mean depths measured in this study. There was also no indication that the accuracy of the tags' depth sensors changed over time.

In addition to the acoustic tags, we used numbered red Peterson disc tags as an external marker. Both acoustic and disc tags were labeled 'Return for Reward' in case of capture by the fishery.

\section{Tagging}

A total of 25 adult Chinook and 51 adult Sockeye salmon were caught and tagged in lower Cook Inlet. Initially, we fished in offshore regions using a commercial troller running six lures on each of the six troll wires; lures were roughly equally spaced from just off bottom to approximately 1 to $2 \mathrm{~m}$ below the surface. In this area, fishing effort was distributed across the Inlet and tags were applied approximately in proportion to the abundance of each species over the migration time period. Chinook capture rates were low, partly due to capture consistently occurring only on the deepest two hooks. These near-bottom lures were often taken by halibut, reducing their efficiency for Chinook. As a result, late in the tagging season we also chartered two inshore sport fishing boats to capture additional maturing Chinook using rod and line in very shallow $(2$ to $3 \mathrm{~m}$ ) waters just off the beach on the eastern side of lower Cook Inlet, near Anchor Point.

Tagging tanks with recirculating pumps and aeration systems were set up. An artificial fish slime (Vidalife ${ }^{\mathrm{rm}}$ ) was introduced into the tank water and spread over tagging surfaces coming in contact with the fish. A light sedative dose of the anesthetic AQUI-S $S^{\circ} 20 \mathrm{E}$ was put in the tank water. (The use of AQUI-S ${ }^{\circ} 20 \mathrm{E}$ was approved under the Investigational New Animal Drug (INAD) program run by the U.S. Aquatic Animal Drug Approval Partnership (AADAP) Program). Because the adult Chinook and Sockeye salmon were found to be quite docile in the tagging sling once they were inverted and a hood covered their eyes, a decision was made in late July that sedation was unnecessary for the remainder of the gastric tagging (that is, for $8 \%$ of Sockeye and $24 \%$ of Chinook).

Captured animals were placed on their back in purposebuilt tagging cradles and hooded, and a hose was placed in their mouths to supply a continuous flow of aerated pumped seawater (see [28] for full details_. Disc tags were attached through the musculature below the dorsal fin. Acoustic tags were implanted into the abdominal cavity of the first three Sockeye Salmon using surgical techniques (1 and 2 July 2013); however, we switched to using a gastric implantation technique for the remainder of the tagging (from 2 July) when we found that the surgical incision tended to gape, probably because of pressure from the developing gonads. After tagging, each fish was measured and then released to the ocean close to their capture location.

\section{Clock-drift correction}

Receiver clock drift is linear and can be easily corrected; we corrected for drift using the automatic correction function in VEMCO's VUE software.

\section{Data screening}

Prior to analysis, we screen the accumulated detection data to identify the following: (1) single transmissions that were recorded on more than one receiver; (2) false detections; (3) the date of displacement for receivers pulled from position (likely by fishing activities) and returned by the public; (4) failed depth sensors; and (5) fish that were likely not of Kenai River origin.

\section{Duplicate detections}

The model of acoustic tags we used were powerful and a single transmission was occasionally detected by more than one receiver. We identified and removed these duplicates from the marine detections so that each successfully decoded transmission would only contribute one observation to the dataset. Duplicates were identified as detections of the same fish at the same depth on neighboring receivers that were recorded within the minimum transmission interval of tag $(<15 \mathrm{~s})$ after the receivers were corrected for clock drift. This screen identified 205 marine detections $(0.94 \%)$ as probable duplicates.

\section{False detection screening}

All telemetry systems may record 'false positives', which are spurious records of the detection of tag ID codes not actually present. Although it can be difficult to unambiguously identify such detections, we screen the detections data prior to analysis to assess their possible presence. We identified and excluded any detection likely to be false using the First and Second Acceptance Criteria recommended by VEMCO (Pincock 2008; see http://www.vemco.com/pdf/false_detections.pdf) with a modification to the Second Criteria. Detections met the first criteria if there was at least one short interval $(<0.5 \mathrm{~h})$ between successive detections of an ID code on a receiver and if there were more short intervals $(<0.5 \mathrm{~h})$ between detections than long ones $(>0.5 \mathrm{~h})$. Detections not meeting the first criteria were then examined individually (second criteria) to determine if they were supported by detections on other sub-arrays in a temporally logical sequence (including release) along the migratory path and if they were recorded when the probability of collision between multiple tags was low (that is, at times when there was a silent interval of $>5$ min on at least one side of the detection in question). VEMCO acoustic tags generally 
have a very low false positive rate: we identified four false detections $(0.016 \%)$ which were all of tag codes not released in this study.

\section{Last date of valid detection screening}

When receivers are accidentally displaced from their deployment position (usually by fishing activity), they may be returned to Kintama by members of the public. We can download the data from these units; however, we do not always know the date and time they were displaced. Fishing crews are often able to provide dates when units were caught in their nets, providing us with accurate displacement dates, but receivers found floating or washed ashore may have been displaced much earlier.

When the date of displacement is not available, we estimate it by comparing the date and time of each tag ID logged with the date and time of the same tag ID on neighboring units that remained in position throughout the study period. The last date with a difference of less than $1 \mathrm{~h}$ between tag detections on neighboring receivers is accepted as the last date of valid detection, and otherwise valid detections recorded for later dates are excluded from any analysis that is sensitive to receiver position. This process can only be used for receivers that have data (empty units cannot be screened) and that have neighboring units that also recorded detections.

In 2013, there were four receivers returned to Kintama by members of the public. From these, we identified 35 detections $(0.14 \%)$ as probably being recorded after the receiver was displaced.

\section{Failed sensor screening}

The pressure sensors malfunctioned in two tagged Chinook and one tagged Sockeye detected by the array (all recorded depths representing a constant depth above the ocean surface), so the pressure data for these animals was excluded from the depth analysis.

\section{Stock of origin screening}

This study focuses on Chinook and Sockeye salmon from the Kenai and Kasilof Rivers; however, fish were captured at sea and the stock of origin was not known at the time of tagging. Tissue samples were collected from each acoustic-tagged fish for genetic stock analysis, but results were problematic for Chinook. Prior to the start of our study, it was assumed that most fish captured in lower Cook Inlet in 2013 would return to the Kenai or Kasilof Rivers, similar to 2012. However, the recapture of a few tagged Chinook south of the tagging area provides evidence that some fish from other stocks were present in our sample. Although in most cases these fish would simply migrate elsewhere and not be detected by the array (that is, they would appear to be mortalities), it is possible that any that did encounter the marine array (for example, stocks from northern Cook Inlet) could exhibit different migration behaviors than Kenai stocks. However, the very consistent behavioral patterns observed for all tagged Chinook suggest that this is unlikely to have a large influence on the results.

To partially address this concern, we removed fish from the analyses $(\mathrm{N}=2$ Chinook; $\mathrm{N}=3$ Sockeye) that were recovered south of the release site; however, we could only remove individuals whose tags were returned. To further focus the results on the Kenai River, we also removed the one Sockeye salmon detected in the Kasilof River.

\section{Data analysis \\ Distribution on marine array}

To identify possible migratory pathways within Cook Inlet, we plotted the number of fish that were detected at each receiver on each of the six east-west lines deployed in the marine array. We also assessed the distribution of fish detected entering the ESSN by plotting fish counts at each receiver along the eastern boundary of the marine array. Because individual fish are usually heard at more than one receiver on a line, we allocated a proportion of each fish to each of the receivers on which it was detected (that is, if a fish was heard once at each of three positions, each unit was allocated 0.33 of a fish).

\section{Migration speeds}

We calculated migration speed ( $\mathrm{km} /$ day) as the ratio of the distance travelled over the travel time. Distance was measured for each fish along the shortest route in water. We calculated travel time for each fish from release until first detection on the marine array, from this first detection on the marine array until arrival at the Kenai River Mouth at RKm 2 (Snug Harbor), and from arrival at one detection site until arrival at the next for all sites in the Kenai River (RKms 2, 4.5, 8.2, 13.8, 22, 25.3, and 30.6). These estimates could only be made for fish detected at both detection sites bracketing the segment in question. Arrival was defined as the first detection at each detection site. For each species, we then used simple linear regression to assess if there was a relationship between migration rate and either tagging date or fork length at tagging.

\section{Migration depth}

In order to quantify how the density of Chinook and Sockeye salmon varied with water depth along the ESSN boundary, we calculated their cumulative depth distribution (CDD). We used each depth transmission as the unit of replication; however, because the number of depth measurements varied by individual fish, there was the possibility that unique behavior by one or a few individuals who were detected frequently could bias the 
results. Accordingly, we assessed the variability in the CDDs by calculating the jackknife distribution for the $m$ fish of each species that were detected by resampling the data $m$ times while successively leaving out all the detections from one individual fish. We then calculated the mean, minimum, and maximum values at each depth across these resampled cumulative distributions.

To further investigate the influence of individual animals, we recalculated the CDDs and assessed their variability as described above using individual fish as the unit of replication. For this approach, we allocated a proportion of each fish to each of its depth transmissions (that is, if a fish was detected 100 times, each detection was weighted as 0.01 ). Thus, the total number of detections for each individual summed to one. Using the fish as the unit of replication in this manner reduced the influence of individuals with high detection counts, but in exchange, individuals for whom we have little information were weighted the same as those whose depth distributions are well known. Results were very similar to those based on individual detections and are detailed in [28].

We then used density histograms in a trellis plot to show the relative distribution of depth detections for both species in relation to daylight and stage of tide. We defined 'high' tides as the top 20th percentile of tide heights predicted for the Kenai River mouth during the interval the tagged fish were migrating over the marine array, and 'low' tides as the bottom 20th percentile of tide heights during this same interval. Times of sunrise and sunset were calculated as the time when the upper edge of the sun's disc coincided with the ideal horizon (that is, ignoring surface topography and variations in weather conditions on actual light levels) at Kenai Airport.

\section{Changes in catch rates with changes in net dimensions}

Because we observed a significant difference in migration depth between the species (see Migration depth under Results), we were able to explore how catch rates might vary with modification to fish gear. We started with a general model where the number of fish caught in a net of length $\mathrm{L}$ and depth $\mathrm{Z}$ is given by

$$
N=\int_{0}^{Z} \int_{0}^{L} e(x, z) \rho(x, z) d x d z
$$

Here, $e(x, z)$ is the efficiency of the net as a function of distance offshore, $x$, and depth, $z$, while $\rho(x, z)$ is the relative abundance of fish as a function of distance and depth. (We neglect fishing time for simplicity).

Lacking receivers in the interior of the ESSN, we assumed that the horizontal distributions of Chinook and Sockeye salmon were uniform within the ESSN zone, and that fish density varied with depth everywhere inside the ESSN as $\rho(\mathrm{z})$, which we have measured along the ESSN boundary (we examine this assumption in the Discussion). If we also assume that the fishing efficiency of the net was constant with distance offshore and depth, $\bar{e}$, this leads to:

$$
N=\int_{0}^{Z} \int_{0}^{L} \bar{e} \cdot k \cdot \rho(z) d x d z=\bar{e} \cdot k \int_{0}^{L} d x \int_{0}^{Z} \rho(z) d z
$$

or

$$
N\left(L_{\max }, Z_{\max }\right)=\bar{e} \cdot k \cdot L_{\max } \int_{0}^{Z_{\max }} \rho(z) d z
$$

Here, $\bar{e} \cdot k$ is the catch per unit length of net at a given fish abundance, $k$. (We assume here that $k$ is timeinvariant to focus on the relative catch rates with different net depths, but this assumption is easily relaxed.)

In (3) we have specified a maximum allowable net length, $\mathrm{L}_{\max }$, and maximum net depth, $\mathrm{Z}_{\max }$. The relative abundance of salmon in the water column, $\rho(\mathrm{z})$, can be approximated from the frequency distribution of all depth measurements for a given species using telemetry tags.

For simplicity, let the proportion of the cumulative depth distribution above some reference depth $\mathrm{z}^{\prime} \leq \mathrm{Z}_{\max }$ be:

$$
\Phi\left(z^{\prime}\right)=\int_{o}^{z^{\prime}} \rho(z) d z
$$

Then the predicted ratio of catches between a net of standard depth and a net of maximum depth $\mathrm{z}^{\prime}$ will be:

$$
\begin{aligned}
\frac{N\left(z^{\prime}\right)}{N_{S \operatorname{tandard}}} & =\frac{\bar{e} \cdot k \cdot L^{\prime} \cdot \Phi\left(z^{\prime}\right)}{\bar{e} \cdot k \cdot L_{S \operatorname{tand} d a r d} \cdot \Phi\left(z_{S \operatorname{tandard}}\right)} \\
& =\frac{L^{\prime} \cdot \Phi\left(z^{\prime}\right)}{L_{S \operatorname{tandard}} \cdot \Phi\left(z_{S \operatorname{tandard} d}\right)}
\end{aligned}
$$

Regulations stipulate a maximum depth of 45 meshes for setnets with individual meshes of $\leq 6$ " $(15.9 \mathrm{~cm})$, and a maximum length of 35 fathoms (64 m); see http://www. adfg.alaska.gov/static/fishing/PDFs/commercial/12uciregs. pdf. For this paper, we have assumed that the standard fishing depth is $5.5 \mathrm{~m}\left(18^{\prime}\right)$ for a 45 mesh net. Assuming that net length and fishing time are not allowed to change, this simplifies to a predicted catch relative to the standard net of:

$$
\frac{N^{\prime}}{N_{S \operatorname{tandard}}}=\frac{\Phi\left(z^{\prime}\right)}{\Phi\left(z_{S \text { tandard }}\right)}
$$

The predicted relative catch thus depends purely upon the depth distribution of each species as the other terms 
cancel in this development. We used equation (5) and the CDDs of Sockeye and Chinook salmon along the ESSN to show the expected baseline harvest for nets of varying depths relative to the $5.5 \mathrm{~m}$ (45 mesh) standard; and equation (4) to show the projected harvest if net length was increased to exactly compensate for the change in net depth.

\section{Availability of supporting data}

Data collected in this study are included as Additional files 5 and 6. Data were also submitted to the Alaska Department of Fish and Game, and are freely available from the authors, with no restrictions placed on use.

\section{Ethics statement}

Use of eugenol (AQUI-S) was approved under an INAD Study Numbers 11-741-13-143 F, 11-741-13-144 F, and 11-741-13-144FA. Fish collection and tagging were conducted under permits issued by the Alaska Department of Fish and Game.

\section{Additional files}

\section{Additional file 1: Animation of salmon movements along the west} coast of North America.

Additional file 2: Animation of salmon movements within Cook Inlet.

Additional file 3: Animation of salmon movements after release to the central Cook Inlet telemetry array.

Additional file 4: Animation showing close-up movements across the telemetry array.

Additional file 5: Tag detection data for 2013 Cook Inlet telemetry study.

Additional file 6: Tag metadata for 2013 Cook Inlet telemetry study.

\section{Abbreviations}

ADF\&G: Alaska Department of Fish and Game; CDD: Cumulative depth distribution; ESSN: Eastside Setnet.

\section{Competing interests}

DWW is President and owner of Kintama Research Services Ltd., an environmental consultancy and the company which designed and developed the major elements of the original POST telemetry array. ADP and PW are employed at Kintama. All authors received a financial benefit in the course of conducting this study and their future salaries depend on their continued technical and scientific performance, which includes the publication of this study. Kintama funded the publication of this article and both holds and is developing new patents in the area of optimal array design to improve the cost-effectiveness and scientific performance of large-scale telemetry arrays.

\section{Authors' contributions}

DWW and PW designed the geometry of the telemetry array and the programming of the acoustic tags. DWW and PW were involved in all aspects of the field work (as were additional staff). DWW and ADP conducted the analyses described in this paper and co-wrote the manuscript. All authors read and approved the final manuscript.

\section{Acknowledgements}

This work was funded by the State of Alaska via a contract administered by the Alaska Department of Fish and Game (ADF\&G). Neither the State of Alaska nor ADF\&G were directly involved in the study design, analysis, or writing of the paper, nor the decision to submit the manuscript for publication. We thank Captain Dave Beam (Cordova; Montague Marine Research, LLC), Casey Pape, and other crew for their able assistance in deploying and recovering the marine array; Mr Ritchie Davis (Juneau; FN West Bank) for his truly humbling skill in trolling; and Mr Steve Walli (Anchor Point) and Dan Calhoun (Homer) for their great willingness to assist on very short notice with additional nearshore sportfish trolling to supplement the number of tagged Chinook Salmon. Mr Mark Willette (ADF\&G) provided very useful help and guidance during the conduct of this pilot study.

Received: 3 September 2014 Accepted: 1 December 2014

Published online: 30 December 2014

\section{References}

1. ADF\&G Chinook Salmon Research Team: Chinook Salmon Stock Assessment and Research Plan, 2013. Anchorage, AK: Alaska Department of Fish \& Game; 2013. Available at: http://www.adfg.alaska.gov/static/home/news/hottopics/ pdfs/chinook_research_plan.pdf.

2. Orsi J: The Alaska Chinook Salmon Production Enigma... What's Going On? ONCORHYNCHUS XXXIII; 2013:1-5. Available at: http://www.afs-alaska. org/wp-content/uploads/Onco332.pdf.

3. Schindler D, Krueger C, Bisson P, Bradford M, Clark B, Conitz J, Howard K Jones M, Murphy J, Myers K, Scheuerell M, Volk E, Winton J: Arctic-YukonKuskokwim Chinook Salmon Research Action Plan: Evidence of Decline of Chinook Salmon Populations and Recommendations for Future Research. Anchorage, AK: AYK Sustainable Salmon Initiative; 2013:v + 70

4. O'Neill D: An in-river look at what has become of the Yukon kings. Alaska J Commerce 2013 November 21. Available at: http://www.alaskajournal.com/ Alaska-Journal-of-Commerce/November-Issue-4-2013/An-in-river-look-atwhat-has-become-of-the-Yukon-kings/.

5. Morris WS: The case for conserving the Kenai king salmon. Alaska J Commerce 2013 November 1. Available at: http://www.alaskajournal.com/ Alaska-Journal-of-Commerce/November-Issue-1-2013/Morris-presents-Thecase-for-conserving-the-Kenai-king-salmon/.

6. McChesney R, Dischner M: Widespread decline points to natural forces on kings. Alaska J Commerce 2013 November 7. Available at: http://www. alaskajournal.com/Alaska-Journal-of-Commerce/November-Issue-2-2013/ Widespread-decline-points-to-natural-forces-on-kings/

7. McChesney R: Questions remain over counts after shift to high-tech sonar. Alaska J Commerce 2013 January 24. Available at: http://www. alaskajournal.com/Alaska-Journal-of-Commerce/December-Issue-2-2013/ Questions-remain-over-counts-after-shift-to-high-tech-sonar/.

8. McChesney R: Kings drive news, but sockeye users drive Inlet economy. Alaska J Commerce 2013 November 14. Available at: http://www. alaskajournal.com/Alaska-Journal-of-Commerce/November-Issue-3-2013/ Kings-drive-news-but-sockeye-users-drive-Inlet-economy/

9. Lowell A: A king without a crown: Chinook vulnerable to ocean forces. Alaska J Commerce 2013 December 24. Available at: http://www. alaskajournal.com/Alaska-Journal-of-Commerce/December-Issue-5-2013/Aking-without-a-crown-Chinook-vulnerable-to-ocean-forces/.

10. Lowell A: Salmon species other than kings thriving around state. Alaska J Commerce 2013 November 7. Available at: http://www.alaskajournal.com/ Alaska-Journal-of-Commerce/November-Issue-2-2013/Salmon-species-otherthan-kings-thriving-around-state/.

11. Dischner M: Fishermen focus on how ADFG sets, achieves escapement goals. Alaska J Commerce 2013 December 18. Available at: http://www. alaskajournal.com/Alaska-Journal-of-Commerce/December-Issue-4-2013/ Fishermen-focus-on-how-ADFG-sets-achieves-escapement-goals/.

12. Dischner M: Alaska salmon management: $A$ unique process for a unique state. Alaska J Commerce 2013 November 26. Available at: http://www. alaskajournal.com/Alaska-Journal-of-Commerce/December-Issue-1-2013/ Alaska-salmon-management-A-unique-process-for-a-unique-state/.

13. Jensen A: Management challenge: Inlet 'fish wars' escalate as king productivity ebbs. Alaska J Commerce 2013 December 12. Available at: http://www.alaskajournal.com/Alaska-Journal-of-Commerce/December-Issue3-2013/Management-challenge-Inlet-fish-wars-escalate-as-king-productivityebbs/.

14. Morris WS: Conserving the Kenai king is a mandate for board, ADFG. Alaska J Commerce 2014 January 9. Available at: http://www.alaskajournal. com/Alaska-Journal-of-Commerce/January-Issue-2-2014/Conserving-theKenai-king-is-a-mandate-for-board-ADFG/. 
15. McChesney F, Dischner M: Kings in cycle: Salmon follow boom and bust pattern. Alaska J Commerce 2013 October 30. Available at: http://www. alaskajournal.com/Alaska-Journal-of-Commerce/November-Issue-1-2013/ Kings-in-cycle-Salmon-follow-boom-and-bust-pattern/.

16. Loring PA: Alternative perspectives on the sustainability of Alaska's commercial fisheries. Conservat Biol 2013, 27:55-63.

17. Loring PA, Harrison HL: "That's what opening day is for": Social and cultural dimensions of (not) fishing for salmon in Cook Inlet, Alaska. Maritime Studies 2013, 12:1-19.

18. Eskelin AA, Miller JD: A qualitative evaluation of parameters used to assess Kenai River king salmon, 1986-2010. Juneau, AK: Alaska Department of Fish and Game, Division of Sport Fish, Research and Technical Services; 2010.

19. Sechrist K, Rutz J: The history of upper Cook Inlet Salmon Fisheries-A century of salmon. Juneau, AK: Alaska Dept of Fish and Game; 2014. Available at: http:// www.adfg.alaska.gov/index.cfm?adfg=wildlifenews.view_article\&articles_id=639.

20. Ogura M, Ishida Y: Homing behaviour and vertical movements of four species of Pacific salmon (Oncorhynchus spp.) in the central Bering Sea. Can J Fish Aquat Sci 1995, 52:532-540.

21. Candy JR, Carter EW, Quinn TP, Riddell BE: Adult Chinook salmon behavior and survival after catch and release from purse-seine vessels in johnstone strait, British Columbia. N Am J Fish Manag 1996, 16:521-529.

22. Candy JR, Quinn TP: Behavior of adult chinook salmon (Oncorhynchus tshawytscha) in British Columbia coastal waters determined from ultrasonic telemetry. Can J Zool 1999, 77:1161-1169.

23. Quinn TP, TerHart BA, Groot C: Migratory orientation and vertical movements of homing adult sockeye salmon (Oncorhynchus nerka) in coastal waters. Anim Behav 1989, 37:587-599.

24. Olson AF, Quinn TP: Vertical and horizontal movements of adult Chinook salmon Oncorhynchus tshawytscha in the Columbia River estuary. Fishery Bulletin 1993, 91:171-178.

25. Wilson S, Hinch S, Drenner S, Martins E, Furey N, Patterson D, Welch D, Cooke $\mathrm{S}$ : Coastal marine and in-river migration behaviour of adult sockeye salmon en route to spawning grounds. Mar Ecol Progr 2014, 496:71-84

26. Drenner SM, Clark TD, Whitney CK, Martins EG, Cooke SJ, Hinch SG: A synthesis of tagging studies examining the behaviour and survival of anadromous salmonids in marine environments. PLOS ONE 2012, 7:e31311

27. Bethe ML, Hansen P: Investigation of Methods and Means to Minimize Chinook Salmon Harvest in the East Side Set Net Fishery of Upper Cook Inlet, 1996. Special Publication 98-3. Juneau, AK: Alaska Dept. of Fish and Game; 1998. Available at: http://www.adfg.alaska.gov/FedAidPDFs/sp98-03.pdf.

28. Welch DW, Porter AD, Winchell P: Chinook and Sockeye Salmon Migration Patterns in Cook Inlet, 2013. Report to the State of Alaska. Juneau, AK: Department of Fish and Game, Division of Commercial Fisheries; 2013. Available at: http://www.legis. state.ak.us/basis/get_documents.asp?session=28\&docid=14913.

29. Strange J: Factors influencing the behavior and duration of residence of adult Chinook salmon in a stratified estuary. Environ Biol Fish 2013, 96:225-243

30. McChesney R: Board adopts further restrictions to Cook Inlet setnet fishery. Alaska J Commerce 2014 February 5. Available at: http://www. alaskajournal.com/Alaska-Journal-of-Commerce/February-Issue-2-2014/ Board-adopts-further-restrictions-to-Cook-Inlet-setnet-fishery/.

31. ADFG: 2014-2017 Cook Inlet Area Commercial Salmon Fishing Regulations. Alaska Dept of Fish and Game: Juneau, AK; 2014. Available at: http://www. adfg.alaska.gov/static/regulations/fishregulations/pdfs/commercial/ 2014_2017_Cook_Inlet_Finfish.pdf.

\section{Submit your next manuscript to BioMed Central and take full advantage of:}

- Convenient online submission

- Thorough peer review

- No space constraints or color figure charges

- Immediate publication on acceptance

- Inclusion in PubMed, CAS, Scopus and Google Scholar

- Research which is freely available for redistribution 